\title{
Risk assessment of Giardia from a full scale MBR sewage treatment plant caused by membrane integrity failure
}

\author{
Yu Zhang ${ }^{1}$, Zhimin Chen ${ }^{1}$, Wei $A n^{1}$, Shumin Xiao ${ }^{2}$, Hongying Yuan ${ }^{2}$, \\ Dongqing Zhang ${ }^{1}$, Min Yang ${ }^{1, *}$
}

1. State Key Laboratory of Environmental Aquatic Chemistry, Research Center for Eco-Environmental Sciences, Chinese Academy of Sciences, Beijing 100085, China. E-mail: zhangyu@rcees.ac.cn

2. Tianjin Key Laboratory of Aquatic Science and Technology, Tianjin Chengjian University, Tianjin 300384, China

\section{A R T I C L E I N F O}

Article history:

Received 19 June 2014

Revised 2 September 2014

Accepted 16 September 2014

Available online 3 February 2015

\section{Keywords:}

Giardia

Reclaimed water

Water quality

Risk

Genotype

\begin{abstract}
A B S T R A C T
Membrane bioreactors (MBR) are highly efficient at intercepting particles and microbes and have become an important technology for wastewater reclamation. However, many pathogens can accumulate in activated sludge due to the long residence time usually adopted in MBR, and thus may pose health risks when membrane integrity problems occur. This study presents data from a survey on the occurrence of water-borne Giardia pathogens in reclaimed water from a full-scale wastewater treatment plant with MBR experiencing membrane integrity failure, and assessed the associated risk for green space irrigation. Due to membrane integrity failure, the MBR effluent turbidity varied between 0.23 and 1.90 NTU over a period of eight months. Though this turbidity level still met reclaimed water quality standards ( $\leq 5 \mathrm{NTU}$ ), Giardia were detected at concentrations of 0.3 to 95 cysts/10 L, with a close correlation between effluent turbidity and Giardia concentration. All $\beta$-giardin gene sequences of Giardia in the WWTP influents were genotyped as Assemblages A and B, both of which are known to infect humans. An exponential dose-response model was applied to assess the risk of infection by Giardia. The risk in the MBR effluent with chlorination was $9.83 \times 10^{-3}$, higher than the acceptable annual risk of $1.0 \times 10^{-4}$. This study suggested that membrane integrity is very important for keeping a low pathogen level, and multiple barriers are needed to ensure the biological safety of MBR effluent.
\end{abstract}

C 2015 The Research Center for Eco-Environmental Sciences, Chinese Academy of Sciences. Published by Elsevier B.V.

\section{Introduction}

Reclaimed water from sewage has become increasingly important in solving water shortage problems in the world. In northern China, a growing number of sewage reclamation facilities have been constructed to produce water for irrigation, toilet flushing, and surface water supplementation (Asano et al., 2013). These efforts, however, are compromised by the water quality problems of reclaimed water, particularly the transport of pathogens through the use of reclaimed water (Rodriguez-Manzano et al., 2012).

Among the frequently encountered water-borne pathogens, protozoan parasites like Giardia sp. have caused particular concerns because the conventional disinfectants like chlorine are ineffective in inactivation of these parasites (Clark and Regli, 1993). Giardia duodenalis (syn. G. intestinalis, G. lamblia) is the only Giardia species found in human gastrointestinal tracts (Monis et al., 2009). It

\footnotetext{
${ }^{*}$ Corresponding author. E-mail: yangmin@rcees.ac.cn (Min Yang).
} 
produces robust cysts, which are voided in the feces and transmitted directly through fecal/oral contact or by ingestion of contaminated water and food (An et al., 2012). Giardia sp. has been detected in sewage (Gassman and Schwartzbrod, 1991; Nasser et al., 2012) as well as in tertiary treatment effluents after chlorination and chloramination (Nasser et al., 2012; Quintero-Betancourt et al., 2003; Ryu et al., 2007).

Both UV and ozonation are efficient in parasite disinfection (Nasser et al., 2012; Linden et al., 2002; Widmer et al., 2009). On the other hand, physical disinfection using membrane filtration has recently been a focus because theoretically it could intercept almost all of the particles larger than its pore size, including pathogenic microbes (Lonigro et al., 2006). The combination of biological wastewater treatment and membrane separation, known as the membrane bioreactor (MBR) process, has attracted particular interest because of its advantages in achieving nutrient removal and disinfection in only one step (Jefferson et al., 2000). However, Jong et al. (2010) reported that microfiltration membranes (pore size $0.45 \mu \mathrm{m}$ ) in MBR did not perfectly remove microorganisms such as Escherichia coli, Salmonella sp., Staphylococcus aureus and Coliform. This could cause particular concerns over the release of pathogens when membrane integrity failure occurs, as pathogens may be concentrated in activated sludge in an MBR system. Lonigro et al. (2006) also detected Giardia and Cryptosporidium in filtered water from an MBR during occasional failure of the ultrafiltration system for treating secondary effluent. Therefore, it will be of importance to assess the risk of Giardia in MBR effluents when a membrane loses its integrity.

In the present study, we surveyed the occurrence of Giardia in reclaimed water from a full-scale wastewater treatment plant (WWTP) with MBR experiencing membrane integrity failure in an industrial park in China, and assessed the associated health risk for green space irrigation. The Giardia genotypes in wastewater were identified using the polymerase chain reaction (PCR) for risk assessment. The results suggested that additional UV or ozonation disinfection should be required to ensure biological safety, as significant membrane leakage occurred due to membrane integrity problems.

\section{Materials and methods}

\subsection{Study facilities and sample collection}

Twelve water samples were taken from the MBR effluent of a full-scale WWTP in an industrial park of Tianjin, China. Commissioning of the plant took place in 2009, and sampling for the risk assessment study was conducted in April, July, August, and November, 2010. Samples were collected daily from 12 July to 16 July and from 22 November to 24 November, and weekly from 12 July to 4 August. The WWTP, which consists of primary treatment, MBR (PVDF hollow fiber membrane with a mean pore size of $0.2 \mu \mathrm{m}$ ) and chlorination in succession, has a capacity of $15,000 \mathrm{~m}^{3}$ per day. The effluent is mainly used for green space irrigation and supplementation to a scenic river in the industrial park. The average mixed liquor suspended solids, hydraulic retention time and sludge retention time were $6000 \mathrm{mg} / \mathrm{L}, 12 \mathrm{hr}$ and 30 days, respectively. The selected water quality parameters for MBR effluents, which were determined according to standard methods for the examination of water and wastewater, were as follows: turbidity, 0.23-1.90 NTU; chemical oxygen demand $\left(\mathrm{COD}_{\mathrm{Mn}}\right), 5.84-10.34 \mathrm{mg} / \mathrm{L} ; \mathrm{NH}_{4}^{+}$: 0.17-0.50 mg/L; dissolved oxygen (DO), $3.86-5.44 \mathrm{mg} / \mathrm{L}$; total coliform, $1.0 \times$ $10^{6}-6.0 \times 10^{6} \mathrm{CFU} / \mathrm{L}$; and fecal coliform, $1.1 \times 10^{4}-9.3 \times 10^{4} \mathrm{CFU} / \mathrm{L}$. The $\mathrm{COD}_{\mathrm{Cr}}$ and $\mathrm{NH}_{4}^{+}$of MBR influent were $184-1177 \mathrm{mg} / \mathrm{L}$ and 6.52-21.19 mg/L, respectively. MBR influent and effluent samples were collected four times (every $6 \mathrm{hr}$ ) per day using automated samplers. All samples were transported to the lab at $4^{\circ} \mathrm{C}$ and treated within $4 \mathrm{hr}$.

\subsection{Giardia detection}

For microscopic inspection, $20 \mathrm{~L}$ MBR effluent was collected each time, and a total of 14 MBR effluent samples were collected for Giardia detection. Three influent samples after primary treatment were taken for Giardia detection $(10 \mathrm{~mL})$ and genotyping (1 L) during the survey, respectively.

Samples were filtered through a mixed cellulose ester membrane filter (diameter, $142 \mathrm{~mm}$; pore size, $1 \mu \mathrm{m}$; Advantec MFS, Inc., Tokyo, Japan) using a peristaltic pump with a typical flow rate of $0.3 \mathrm{~L} / \mathrm{min}$. After filtration, the membrane filter was transferred to a fresh screw-capped conical 50-mL centrifuge tube and transported on ice to the laboratory for further processing within $72 \mathrm{hr}$ (USEPA, 2005). The membrane filters were dissolved in acetone solutions to recover Giardia, as described previously (Hashimoto et al., 2002). The detection of Giardia was conducted according to previous studies (Hashimoto et al., 2002; Xiao et al., 2012). A detailed description of the microscopic detection method for Giardia is provided in Appendix A. Supplementary data.

Method blanks $(n=3)$ and initial precision and recovery (IPR) tests $(n=4)$ were included prior to the initiation of field sampling. For the IPR tests, $10 \mathrm{~L}$ of reagent water was spiked directly with Giardia stock suspension (Waterborne Inc., New Orleans, LA, USA). The mean recovery for IPR tests was $24 \%-$ 95\%, which met USEPA acceptance criteria (USEPA, 2005) and Chinese standards.

\subsection{Preparation of DNA templates and PCR assay}

Molecular analysis was performed on three wastewater samples. Genomic DNA was extracted from Percoll-sucrose flotation-purified cysts of concentrated water samples using the FastDNA SPIN kit for soil (MP Biomedicals, Strabourg, France), according to the manufacturer's instructions. In addition, six freeze-thaw cycles (liquid nitrogen $2 \mathrm{~min} / 56^{\circ} \mathrm{C}$, $5 \mathrm{~min}$ ) were conducted after resuspension in lysis solution to rupture the Giardia cysts. DNA was eluted in 50-100 $\mu \mathrm{L}$ buffers and stored at $-20^{\circ} \mathrm{C}$ for further processing.

Amplification of the $\beta$-giardin gene was performed using a nested PCR protocol. In the primary PCR reaction, a $753 \mathrm{bp}$ fragment was amplified using forward primer G7 and reverse primer G759, as previously described (Lalle et al., 2005). In the sequential nested PCR reaction, a 511 bp fragment was amplified using forward primer 5'-GAACGAGATCGAGGTCCG-3' and reverse primer 5'-CTCGACGAGCTTCGTGTT-3'. The primers were chosen to match two conserved regions in a multiple alignment of $\beta$-giardin nucleotide sequences representing Assemblages A, B and E. Briefly, primary PCR amplifications were performed in $50-\mu \mathrm{L}$ volumes using Taq polymerase with $1 \times$ Taq buffer (TaKaRa, Dalian, China) and containing $1.5 \mathrm{mmol} / \mathrm{L} \mathrm{MgCl}_{2}$, and $200 \mu \mathrm{mol} / \mathrm{L}$ each of diethyl nitrophenyl thiophosphate (dNTP), $0.4 \mathrm{mg} / \mathrm{mL} \mathrm{BSA}$, and $0.1 \mu \mathrm{mol} / \mathrm{L}$ primers. After an initial denaturation at $95^{\circ} \mathrm{C}$ for $5 \mathrm{~min}$, the cycling program consisted of 35 cycles of denaturation at $95^{\circ} \mathrm{C}$ for $30 \mathrm{sec}$, annealing at $65^{\circ} \mathrm{C}$ for primary $\mathrm{PCR}\left(55^{\circ} \mathrm{C}\right.$ for secondary nested PCR) for $30 \mathrm{sec}$, and primer extension at $72^{\circ} \mathrm{C}$ for $1 \mathrm{~min}$. A 
final extension cycle at $72^{\circ} \mathrm{C}$ for $7 \mathrm{~min}$ was followed by soaking at $4^{\circ} \mathrm{C}$. Three PCR replicates per sample, using $1-3 \mu \mathrm{L}$ of extracted DNA per PCR, were performed to increase Giardia detection accuracy. One milliliter of primary PCR product was used as the template for the secondary nested PCR. The nested PCR products were analyzed after electrophoresis in $1.5 \%$ agarose gels and staining with $0.2 \mu \mathrm{g} / \mathrm{mL}$ of ethidium bromide, and visualized on a UV transilluminator.

\subsection{Sequence and phylogenetic analysis}

The secondary PCR products positive for Giardia were purified with a DNA UNIQ-5 spin column purification kit (Tiangen Biotech, Beijing, China) and cloned into the pMD18-T plasmid vector using a cloning kit (Takara, Dalian, China), according to the manufacturer's recommendations. Clones were sent to Beijing AuGCT Co., Ltd., China, for sequencing using an ABI 3730 automated DNA sequencer (BigDye Terminator Chemistry, Life technologies, NY, USA). Nucleotide sequences were read using Chromas software (http://www.technelysium.com. au, Technelysium Pty Ltd, South Bribane, Australia). The obtained sequences, with other reference sequences downloaded from the GenBank database, were aligned using Clustal W (http://www.clustal.org) programs. Phylogenetic trees were constructed using MEGA version 5.0 (Molecular Evolutionary Genetics Analysis software, Arizona State University, Tempe, Arizona, USA). Bootstrap analyses were conducted using 1000 replicates to assess the reliability of inferred tree topologies. Neighbor-Joining algorithms were conducted using the Kimura 2 parameter distance analysis. Sequences representing assemblages $\mathrm{A}-\mathrm{F}$ were obtained from the GenBank database (National Center for Biotechnology Information, NCBI, www.ncbi.nlm.nih.gov) for G. duodenalis at the $\beta$-giardin loci and from a previous review (Wielinga and Thompson, 2007).

\subsection{Risk assessment of Giardia}

Exposure assessment is the estimation of how likely an individual or population is to be exposed to an identified hazard and what quantity is likely to be ingested. In recent years, the methodology for the risk assessment of pathogens has been well established to enable better management of the safety of food, water, human and animal wastes, reclaimed water, etc., with respect to microbial contamination (USDA/FSIS and USEPA, 2012). In this study, only green space irrigation exposure was considered. An exponential dose-response model was used (Haas, 1983). This model was based on human volunteer trials that provided the necessary infectivity data and proposed that the daily probability of infection, $p$, was functionally related to daily ingested dose, $d$ (in cysts), as follows:

$p=1-\exp (-d / k)$

where, $k$ is a function parameter with a proposed best value of 50.5 and a $95 \%$ confidence interval of 27.9 to 102.1 . The best value of $k$ provides a good fit to infectivity data (Rose et al., 1991).

The annual risk of infection over time due to multiple independent exposures was modeled as (Rose and Gerba, 1991):

$P_{n}=1-(1-p)^{n}$ where, $P_{n}$ is the overall probability of infection and $n$ is the number of exposures ( $n=52$ per year, once a week).

The average exposure (d) to cysts was estimated using the following equation:

$d=C \times 10^{-\mathrm{DR}} \times V$

where, $d$ is the number of cysts ingested daily by a person through reclaimed water from green space irrigation, $C$ (cysts/L) is the concentration of pathogens, DR is the disinfection efficiency $(0.5,3.0$, and 3.0 log-unit removal credits were considered for chlorination, UV irradiation and ozonation, respectively (Ryu et al., 2007; USEPA, 1989)) and V (L) is accidental consumption of a small amount of reclaimed water. The amount of reclaimed water ingested for green space irrigation was estimated at $0.005 \mathrm{~L}$ per outing (Ryu et al., 2007). The Poisson probability distribution model used to describe the count data of microbes (Consul and Famoye, 2006) was applied to describe the prevalence of Giardia cysts in reclaimed water (Eq. (1)). There was no provision for the potential die-off of Giardia cysts by desiccation, sunlight, predation or other reasons because of the extreme resistance of the thick-walled cysts to environmental factors. The applied level of acceptable annual risk was $1.00 \times 10^{-4}$. This is the annual risk established in the Surface Water Treatment Rule for domestic water supply (USEPA, 1989).

\section{Results and discussion}

\subsection{Occurrence of Giardia in reclaimed water samples}

Table 1 presents the concentration levels of $G$. duodenalis in the MBR effluents. A total of 12 samples were examined by microscopy, with Giardia detected in all samples (100\%). A Giardia concentration of 3 to 95 cysts/10 L was detected during the survey (April to November, 2010), which was high in comparison with that $(0.046-3.65$ cysts/10 L) in non-potable reclaimed water after tertiary treatment in the southwestern United States (Ryu et al., 2007). The prevalence of Giardia cysts in the samples was fitted by a Poisson distribution with $P<0.05$ by Chi-Square test $(\lambda=60 ; R$ statistic software). This result indicated the prevalence of Giardia cysts in the studied

Table 1-Concentration of Giardia in reclaimed water samples from the membrane bioreactor (MBR) effluents.

Sample time $(\mathrm{dd} / \mathrm{mm} / \mathrm{yy})$ No. of cysts/L MBR effluent

$\begin{array}{ll}13 / 4 / 2010 & 8.3 \\ 12 / 7 / 2010 & 7.5 \\ 13 / 7 / 2010 & 5.9 \\ 14 / 7 / 2010 & 7.3 \\ 15 / 7 / 2010 & 8.4 \\ 16 / 7 / 2010 & 9.5 \\ 21 / 7 / 2010 & 5.2 \\ 28 / 7 / 2010 & 8.0 \\ 4 / 8 / 2010 & 2.1 \\ 22 / 11 / 2010 & 0.3 \\ 23 / 11 / 2010 & 9.1 \\ 24 / 11 / 2010 & 1.2\end{array}$


effluents. It should be noted that high Giardia concentrations (645 and 155 cysts/10 L) were detected in the MBR effluent together with a high turbidity (25.9 and 4.7 NTU) on January and March, 2010 during the commissioning stage of the WWTP, suggesting the occurrence of severe failure of membrane filtration. Leakage testing of the membrane system by the WWTP revealed the occurrence of fiber breakage and disconnections in the membrane modules. After overhauling of the MBR system in April, decreased Giardia concentrations (3-95 cysts/10 L) were observed together with decreased turbidity (0.23-1.90 NTU) as shown in Table 1 and Fig. 1. Theoretically, an intact MBR (average membrane pore size $0.01-0.4 \mu \mathrm{m}$ ) is a barrier to pathogens and suspended solids larger in size than the membrane pore size, and therefore can offer better pathogen removal than conventional treatment. As a result, total coliform reduction can reach an average of log7 (Hirani et al., 2010). However, our study showed that high concentrations of Giardia $(>4 \mu \mathrm{m}$ ) could occur in the MBR effluent caused by membrane integrity failure. Lonigro et al. (2006) also found Giardia and Cryptosporidium in filtered water during occasional failure of the ultrafiltration system for treating secondary effluent.

The turbidity of reclaimed water has often been used as an indicator for biological safety and membrane integrity (Antony et al., 2012; Naismith, 2005). Theoretically, a MBR could achieve almost complete solid-liquid separation, and turbidity for a functional MBR is usually below $0.2 \mathrm{NTU}$ (or even lower). However, the turbidity of $0.23-1.90 \mathrm{NTU}$ is abnormally high for MBR permeation. As shown in Fig. 1, the Giardia concentration was significantly correlated with turbidity in the collected water samples $\left(R^{2}=0.7666, P<0.05\right)$, which was consistent with previous research on drinking water (Carmena et al., 2007). Therefore, the turbidity of MBR effluent should be closely related to membrane module integrity. Although effluent turbidity (0.23-1.90 NTU) in the present study satisfied wastewater reclamation standards (NTU $\leq 5$, GB/T 25499-2010, China), Giardia may leak from the MBR system at a relatively high concentration. Turbidities of $1.5 \pm 0.4$ and $0-6$ (average 1.63) NTU in effluents have also been reported for MBR effluents with pore size $<0.4$ and $0.45 \mu \mathrm{m}$, respectively (Jong et al., 2010; Rodríguez-Hernández

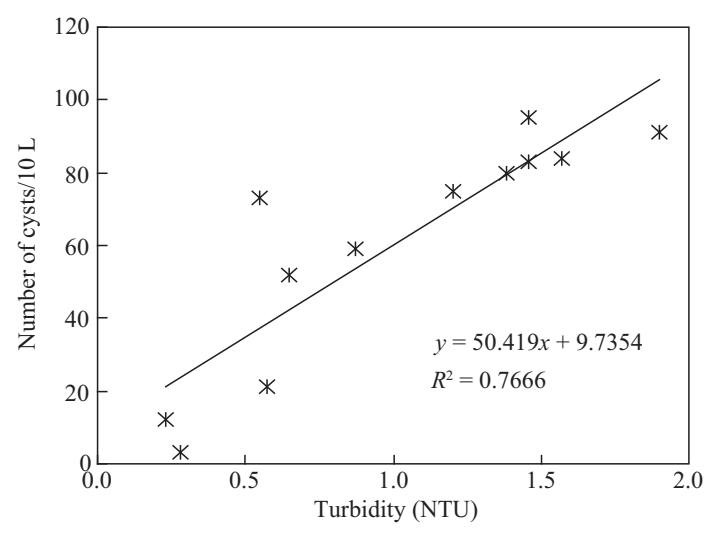

Fig. 1 - Correlation between turbidity and Giardia concentration in the MBR effluent samples. et al., 2013), suggesting that leakage of particles may be a frequently occurring problem in actual application. This is understandable since membranes are under stress (e.g., high shear stress, existence of sharp particles) in an MBR system.

Antony et al. (2012) reported that membrane damage during membrane operation could generate virus breakthrough. They concluded that any anomaly in the membrane surface (e.g., abnormally big pores, compromised glue line, holes) and the filtration system (e.g., compromised O-rings, broken mechanical seals) results in microbial contamination risk for the product water. Therefore, monitoring membrane treatment system integrity is essential for the protection of public health from microbial risk. In particular, occasional failure of MBR systems may cause serious problems since many pathogens - mainly viruses and protozoa - can accumulate in activated sludge at high concentrations due to the long sludge retention times usually adopted in the process (Marti et al., 2011). Leakage of Giardia cysts could be reduced by maintaining membrane integrity (Lonigro et al., 2006).

On the other hand, the Giardia concentration in WWTP influent (after primary treatment) was 22,000 cysts/10 L in the present study. Nasser et al. (2012) reported that in 23 out of 30 studies, all tested raw wastewater samples were positive for Giardia, at concentrations ranging from 2.3 to 1,000,000 cysts/10 L, showing that Giardia pollution is quite universal and requires effective control to secure the biological safety of reclaimed water. Giardia concentrations in raw wastewater and primary, secondary and tertiary treatment effluents were 1300-36,000, 5330-20,330, 0-320 and 0-21 cysts/10 L, respectively, in three municipal wastewater treatment plants in Beijing, China (Fu et al., 2010). Thus, significant removals of Giardia were achieved through secondary and tertiary treatment, showing the importance of establishing multiple barriers for pathogen control. Therefore, a disinfection system is proposed as an additional barrier to ensure the safety of MBR effluent.

\subsection{Exposure assessment of Giardia}

The average Giardia concentration in reclaimed water was 60.7 cysts/10 L during the survey. The daily and annual risks of infection associated with Giardia were calculated using the exponential dose-response model (Table 2). The annual acceptable risk of infection of $1.00 \times 10^{-4}$ from water-borne exposure through potable water was applied for performing risk characterizations (Rose and Gerba, 1991; USEPA, 1989). Annual risk with chlorination $\left(9.83 \times 10^{-3}\right)$ was high in comparison with the suggested annual acceptable microbial risk of infection. The annual risks could be reduced to acceptable levels by combining ozonation or UV $\left(3.13 \times 10^{-5}\right)$ (Table 2). Despite the fact that turbidity met the standard of reclaimed water for green space irrigation, the risk of infection by Giardia in the MBR effluents (chlorine) was still at an unacceptable level. Adding a barrier like UV irradiation or ozonation to the MBR system helped ensure the biological safety of reclaimed water.

\subsection{Molecular identification and genotyping of Giardia}

To identify the genotypes and possible transmission patterns of Giardia, PCR amplification was performed for Giardia from influent samples after primary treatment. Twenty positive 
Table 2 - Annual risks of Giardia infection from reclaimed water used in green space irrigation during the survey.

\begin{tabular}{lcccc}
\multicolumn{1}{c}{ Sample } & $\begin{array}{c}\text { Average } \\
\text { cysts/L }\end{array}$ & $\begin{array}{c}\text { Disinfection } \\
\text { efficiency }\end{array}$ & $\begin{array}{c}\text { Daily } \\
\text { risk }\end{array}$ & $\begin{array}{c}\text { Annual } \\
\text { risk }\end{array}$ \\
\hline $\begin{array}{l}\text { MBR effluent } \\
\text { (chlorine) }\end{array}$ & 6.07 & 0.5 & $1.90 \times 10^{-4}$ & $9.83 \times 10^{-3}$ \\
$\begin{array}{l}\text { MBR effluent } \\
\text { (ozonation/ } \\
\text { chlorine) }\end{array}$ & 6.07 & 3 & $6.01 \times 10^{-7}$ & $3.13 \times 10^{-5}$ \\
$\begin{array}{l}\text { MBR effluent } \\
\text { (UV/chlorine) }\end{array}$ & 6.07 & 3 & $6.01 \times 10^{-7}$ & $3.13 \times 10^{-5}$ \\
\hline
\end{tabular}

clone sequences were obtained by sequence analysis of the nested PCR products of the $\beta$-giardin gene. According to sequence analysis (Fig. 2), eighteen sequences were genotyped as Assemblage A and two as Assemblage B, which were in accordance with previous wastewater studies (Sulaiman et al., 2004). All clones exhibited more than $99 \%$ identity with known $\beta$-giardin gene sequences in NCBI (http://blast.ncbi.
nlm.nih.gov/Blast.cgi). Nine clone sequences exhibited 100\% identity with the representative sequence for Assemblage A (FN386482). The two clones belonging to Assemblage $B$ (Clone 1 and Clone 12) had two bases different from the representative sequence (EU637579).

Considerable data have shown that $G$. duodenalis should be considered as a species complex, whose members, although morphologically identical, can be assigned to at least eight distinct Assemblages (A-H) based on genetic analyses (genotypes) (Monis et al., 2009; Xiao and Fayer, 2008). Assemblages $\mathrm{A}$ and $\mathrm{B}$ can infect humans and a variety of mammals, whereas Assemblages $\mathrm{C}$ to $\mathrm{H}$ are considered to be nonhuman host-specific (Monis et al., 2009; Sulaiman et al., 2004; Xiao and Fayer, 2008). On the other hand, it is unlikely that all Giardia detected in the water samples were human-pathogenic species. The probability of infection may be overestimated (Ryu et al., 2007) since microscopic detection for risk assessment of Giardia does not differentiate among Giardia species. Thus, molecular genotyping of the detected Giardia in the water samples

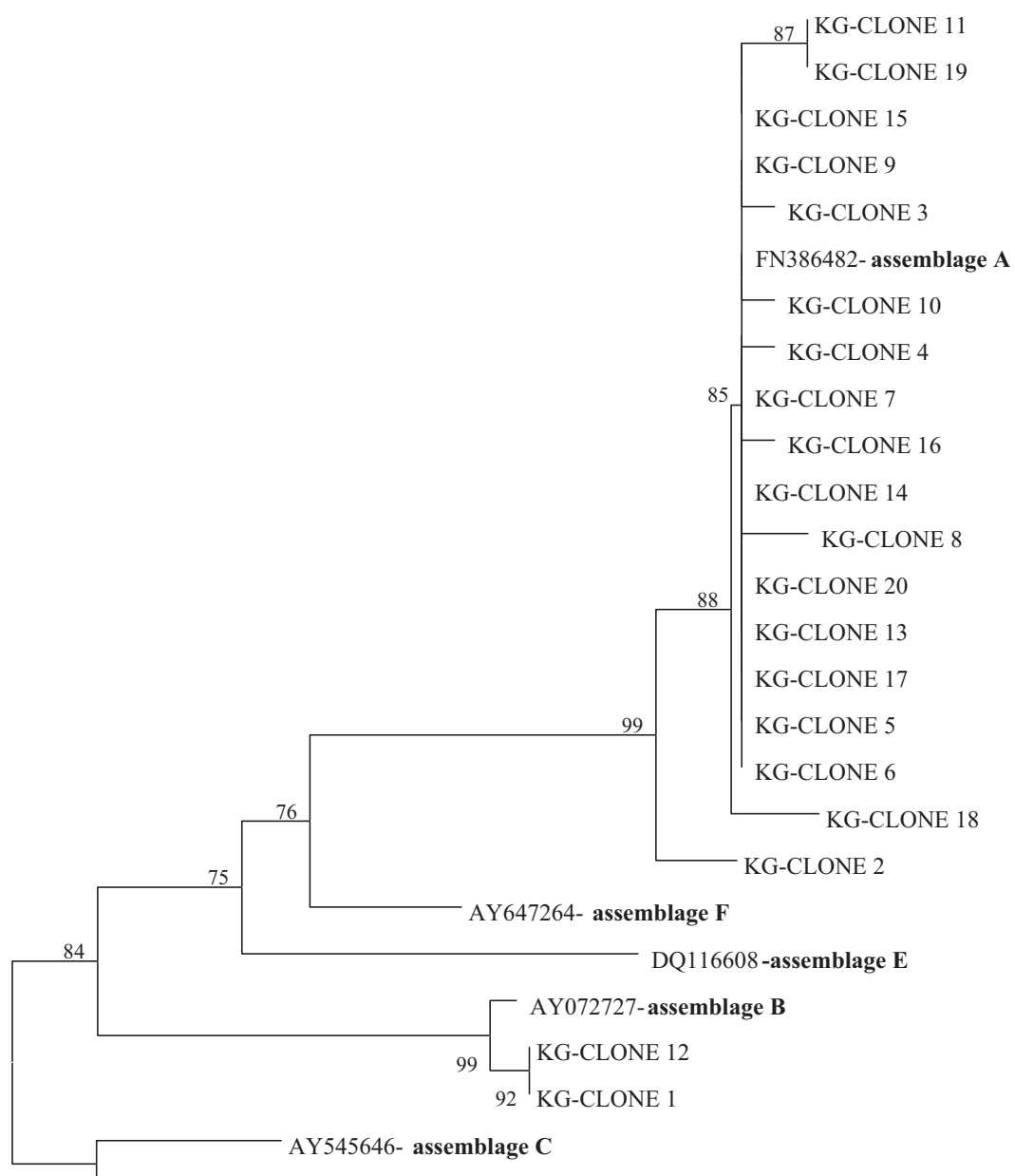

AY370531- assemblage D

0.005 substitutions per site

Fig. 2 - Phylogenetic analysis of Giardia inferred by neighbor-joining analysis of partial $\beta$-giardin gene sequences. Evolutionary distances between sequences were calculated by the Kimura two-parameter model. Values on branches are bootstrapping value percentages $(>50 \%)$ using 1000 replicates. 
will help reduce uncertainty in Giardia risk assessment. The predominance of $G$. duodenalis Assemblages A and B in the present study showed that the contaminant source in this study may have originated from humans, stressing the potential risk associated with the use of reclaimed water.

\section{Conclusions}

The results of this study showed that the risk of infection by Giardia for green space irrigation exceeded the annual acceptable risk in the studied MBR effluents with chlorine disinfection when the membrane lost its integrity. Genotype analysis based on the $\beta$-giardin gene revealed that the human-infective $A$ and $B$ assemblages were the main genotypes in wastewater, stressing the potential risk associated with the use of the MBR effluents with a high level of membrane integrity failure. Ozonation or UV was required to ensure the biological safety of the reclaimed MBR effluent. The above results showed that the monitoring of membrane integrity in MBR is very important for the biological safety of the MBR effluent, and establishing multiple barriers in treatment of wastewater is necessary for MBR.

\section{Acknowledgments}

This work was supported by the Creative Research Groups of China (No. 51221892, 21277169).

\section{Appendix A. Supplementary data}

Supplementary data associated with this article can be found in online version at http://dx.doi.org/10.1016/j.jes.2014.09.033.

\section{R E F E R E N C E S}

An, W., Zhang, D.Q., Xiao, S.M., Yu, J.W., Yang, M., 2012. Risk assessment of Giardia in rivers of southern China based on continuous monitoring. J. Environ. Sci. 24 (2), 309-313.

Antony, A., Blackbeard, J., Leslie, G., 2012. Removal efficiency and integrity monitoring techniques for virus removal by membrane processes. Crit. Rev. Environ. Water Sci. Technol. 42 (9), 891-933.

Asano, T., Bahri, A., Anderson, J., 2013. Milestones in Water Reuse: The Best Success Stories. IWA Publishing, London, UK.

Carmena, D., Aguinagalde, X., Zigorraga, C., Fernández-Crespo, J., Ocio, J., 2007. Presence of Giardia cysts and Cryptosporidium oocysts in drinking water supplies in northern Spain. J. Appl. Microbiol. 102 (3), 619-629.

Clark, R.M., Regli, S., 1993. Development of Giardia C $\bullet$ t values for the surface water treatment rule. J. Environ. Sci. Health A 28 (5), 1081-1097.

Consul, P.C., Famoye, F., 2006. Lagrangian Probability Distributions. Birkhäuser Publish, Boston.

Fu, C.Y., Xie, X., Huang, J.J., Zhang, T., Wu, Q.Y., Chen, J.N., Hu, H.Y., 2010. Monitoring and evaluation of removal of pathogens at municipal wastewater treatment plants. Water Sci. Technol. 61 (6), 1589-1599.

Gassman, L., Schwartzbrod, J., 1991. Wastewater and Giardia cysts. Water Sci. Technol. 24 (2), 183-186.
Haas, C.N., 1983. Estimation of risk due to low doses of microorganisms: a comparison of alternative methodologies. Am. J. Epidemiol. 118 (4), 573-582.

Hashimoto, A., Kunikane, S., Hirata, T., 2002. Prevalence of cryptosporidium oocysts and Giardia cysts in the drinking water supply in Japan. Water Res. 36 (3), 519-526.

Hirani, Z.M., DeCarolis, J.F., Adham, S.S., Jacangelo, J.G., 2010. Peak flux performance and microbial removal by selected membrane bioreactor systems. Water Res. 44 (8), 2431-2440.

Jefferson, B., Laine, A.L., Judd, S.J., Stephenson, T., 2000. Membrane bioreactors and their role in wastewater reuse. Water Sci. Technol. 41 (1), 197-204.

Jong, J., Lee, J., Kim, J., Hyun, K., Hwang, T., Park, J., Choung, Y., 2010. The study of pathogenic microbial communities in graywater using membrane bioreactor. Desalination 250 (2), 568-572.

Lalle, M., Pozio, E., Capelli, G., Bruschi, F., Crotti, D., Cacciò, S.M., 2005. Genetic heterogeneity at the $\beta$-giardin locus among human and animal isolates of Giardia duodenalis and identification of potentially zoonotic subgenotypes. Int. J. Parasitol. 35 (2), 207-213.

Linden, K.G., Shin, G.A., Faubert, G., Cairns, W., Sobsey, M.D., 2002. UV disinfection of Giardia lamblia cysts in water. Environ. Sci. Technol. 36 (11), 2519-2522.

Lonigro, A., Pollice, A., Spinelli, R., Berrilli, F., Di Cave, D., D’Orazi, C., et al., 2006. Giardia cysts and cryptosporidium oocysts in membrane-filtered municipal wastewater used for irrigation. Appl. Environ. Microbiol. 72 (12), 7916-7918.

Marti, E., Monclús, H., Jofre, J., Rodriguez-Roda, I., Comas, J., Balcázar, J.L., 2011. Removal of microbial indicators from municipal wastewater by a membrane bioreactor (MBR). Bioresour. Technol. 102 (8), 5004-5009.

Monis, P.T., Caccio, S.M., Andrew Thompson, R.C., 2009. Variation in Giardia towards a taxonomic revision of the genus. Trends Parasitol. 25 (2), 93-100.

Naismith, J., 2005. Membrane integrity-direct turbidity measurement of filtrate from membrane modules at an operating potable water treatment plant. Desalination 179 (1-3), 25-30.

Nasser, A., Vaizel-Ohayon, D., Aharoni, A., Revhun, M., 2012. Prevalence and fate of Giardia cysts in wastewater treatment plants. J. Appl. Microbiol. 113 (3), 477-484.

Quintero-Betancourt, W., Gennaccaro, A., Scott, T., Rose, J., 2003. Assessment of methods for detection of infectious Cryptosporidium oocysts and Giardia cysts in reclaimed effluents. Appl. Environ. Microbiol. 69 (9), 5380-5388.

Rodríguez-Hernández, L., González-Viar, M., De Florio, L., Tejero, I., 2013. Hybrid membrane bioreactor application for decentralized treatment and reuse. Desalin. Water Treat. 51 (10-12), 2467-2473.

Rodriguez-Manzano, J., Alonso, J., Ferrús, M., Moreno, Y., Amorós, I., Calgua, B., et al., 2012. Standard and new faecal indicators and pathogens in sewage treatment plants, microbiological parameters for improving the control of reclaimed water. Water Sci. Technol. 66 (12), 2517-2523.

Rose, J.B., Gerba, C.P., 1991. Use of risk assessment for development of microbial standards. Water Sci. Technol. 24 (2), 29-34.

Rose, J.B., Haas, C.N., Regli, S., 1991. Risk assessment and control of waterborne Giardiasis. Am. J. Public Health 81 (6), 709-713.

Ryu, H., Alum, A., Mena, K., Abbaszadegan, M., 2007. Assessment of the risk of infection by cryptosporidium and Giardia in non-potable reclaimed water. Water Sci. Technol. 55 (1), 283-290.

Sulaiman, I.M., Jiang, J., Singh, A., Xiao, L., 2004. Distribution of Giardia duodenalis genotypes and subgenotypes in raw urban wastewater in Milwaukee, Wisconsin. Appl. Environ. Microbiol. 70 (6), 3776-3780.

USDA/FSIS, USEPA, 2012. Microbial Risk Assessment Guideline: Pathogenic Organisms with Focus on Food and Water 
(FSIS Publication No. USDA/FSIS/2012-001; EPA Publication No. EPA/100/J12/001).

USEPA, 1989. Surface Water Treatment Rule (Washington DC). USEPA, 2005. Method 1623: Cryptosporidium and Giardia in Water by Filtration/Ims/Fa. EPA 815-R-05-002, Washington DC. Widmer, G., Clancy, T., Ward, H.D., Miller, D., Batzer, G.M., Pearson, C.B., et al., 2009. Structural and biochemical alterations in Giardia lamblia cysts exposed to ozone. J. Parasitol. 88 (6), 1100-1106.
Wielinga, C.M., Thompson, R.C., 2007. Comparative evaluation of Giardia duodenalis sequence data. Parasitology 134 (12), 1795-1821.

Xiao, L., Fayer, R., 2008. Molecular characterisation of species and genotypes of Cryptosporidium and Giardia and assessment of zoonotic transmission. Int. J. Parasitol. 38 (11), 1239-1255.

Xiao, S.M., An, W., Chen, Z.M., Zhang, D.Q., Yu, J.W., Yang, M., 2012. Occurrences and genotypes of cryptosporidium oocysts in river network of Southern-Eastern China. Parasitol. Res. 110 (5), 1701-1709. 